\title{
Ensino de Língua Portuguesa: reflexões sobre a necessidade de análise crítica de textos $^{1}$
}

\section{The Teaching of Portuguese: Reflections on the Need for a Critical Analysis of Texts}

Adriane Teresinha Sartori*

Universidade Federal de Minas Gerais

Belo Horizonte, Minas Gerais, Brasil

RESUMO: Este artigo analisa episódios de aulas de língua portuguesa vivenciados por um grupo de trabalho durante os anos de 2013 e 2014, em escolas públicas de Belo Horizonte. Analisados sob perspectiva qualitativa, os dados revelam a forma como professores e alunos lidam com textos que circulam na sociedade. A análise sugere que, tendo gêneros discursivos ou metalinguagem como objeto de ensino, o processo pedagógico exige atenção àquilo que alunos e professores constroem discursivamente diante da tarefa de ensinar-aprender língua portuguesa, além de nos possibilitar defender a necessidade de efetivarmos práticas de análise crítica de textos no cotidiano escolar.

PALAVRAS-CHAVE: ensino de língua portuguesa; gêneros discursivos; análise crítica de textos.

\begin{abstract}
This article analyzes episodes in Portuguese language classes, which were experienced by a work group throughout 2013 and 2014, in public schools in Belo Horizonte, Brazil. The data were analyzed from a qualitative perspective and revealed the way that teachers and students deal with texts that circulate within society. The analysis suggests that, while taking discursive genres or metalanguage as the object of study, the pedagogical procedure requires attention to what students and teachers construct discursively when faced with the task of teaching and learning Portuguese, as well as making it possible to make the case for a critical analysis of thexts in the day-to-day context of schooling.
\end{abstract}

KEYWORDS: teaching of Portuguese; discursive genres; critical analysis of texts.

* adriane.sartori@gmail.com

${ }^{1}$ Este texto é uma versão revista e ampliada, com análise de dados inéditos, de artigo publicado em Anais do CD-ROM: 90 CONGRESO INTERNACIONAL DE EDUCACIÓN SUPERIOR, 2014, Havana. Memorias - Universidade 2014. V Taller Internacional de Formación Universitaria de profesionales de la Educación. (CD-ROM). 


\section{Introdução}

$\mathrm{Na}$ atualidade, há um discurso quase hegemônico entre especialistas de ensino e documentos oficiais quanto à matéria-prima que deva fomentar o ensino da língua materna na escola, os gêneros textuais. Embora as concepções de gênero sejam diversas, tanto pesquisadores acadêmicos quanto textos orientadores parecem convergir para a necessidade de a leitura e a escrita de gêneros variados serem o foco do trabalho didático-pedagógico com a língua. Assim, se até bem pouco tempo a discussão central estava em ministrar ou não aulas de gramática, temos, na atualidade, a definição consensual de um "novo" objeto de ensino, os gêneros.

No entanto, nossa observação e a análise de aulas de língua portuguesa nos permitem afirmar que, apesar do alinhamento entre documentos e a maioria dos especialistas, os gêneros não são o único objeto de ensino nas escolas. Na realidade, a sala de aula da educação básica se constitui uma variedade de práticas, uma verdadeira "bricolagem" (CERTEAU, 2000) de teorias e saberes. Notícia, reportagem, tirinha, substantivo, adjetivo, advérbio, anafórico, modalizador, tipo e gênero textual são conceitos encontrados em aulas de língua materna, resultado de teorias diversas, produzidos por docentes que precisam responder às adversidades e aos desafios do dia a dia da sala de aula, refletindo e refratando a complexidade do cotidiano escolar.

Nesse emaranhado de lógicas, saberes, discursos e ideias que constituem as práticas escolares, propomo-nos a discutir, neste artigo, três situações vivenciadas, em 2013 e em 2014, no âmbito do Projeto de Extensão "Professor universitário e da educação básica, aluno de graduação e de escola: um encontro necessário", desenvolvido na Universidade Federal de Minas Gerais. Nesse projeto, um docente de ensino superior, professores de língua portuguesa da educação básica e alunos de graduação da universidade encontram-se semanalmente, nas escolas, para analisar trabalhos de alunos de ensino médio e aulas ministradas, visando construir propostas de solução para os problemas diagnosticados, a partir de uma visão interacionista de língua e de educação. Esses encontros, concretizando uma pesquisa-ação (THIOLLENT, 2007), são registrados em diário de campo, instrumento que descreve os relatos e as discussões realizadas.

Mais especificamente, neste trabalho, pretendemos discutir como um processo de análise crítica precisa ser concretizado nas brechas do já historicamente instituído, sob pena de continuarmos a ser, no fazer cotidiano da escola e da universidade, meros transmissores de um conteúdo 
pretensamente neutro. É pressuposto desse trabalho, portanto, que a formação profissional - inicial ou continuada - faz-se em processo e deva partir da prática, discutindo o que se diz/faz em sala de aula, vislumbrando alternativas do que se poderia (ou não) dizer/fazer, quando se pensa efetivamente na necessidade de ampliação de horizontes de alunos e professores, visando, em última instância, a mudanças significativas no ensino de língua portuguesa e na sociedade, visto que um projeto educativo é sempre um projeto de sociedade (GERALDI, 2010a).

Este texto está organizado em quatro seções principais. Na primeira, buscamos fundamentar teoricamente o trabalho, apresentando as ideias essenciais ligadas ao ensino de língua portuguesa e ao conceito de letramento e letramento crítico; na segunda, definimos a ancoragem metodológica; na seguinte, transcrevemos os extratos de nosso diário de campo, buscando analisá-los; no final, mencionamos algumas contribuições da nossa pesquisa para o ensino de língua portuguesa.

\section{Ensino de língua portuguesa e letramento (crítico)}

Em 1984, Geraldi publica o livro "O texto na sala de aula", marco da virada pragmática que se realiza - ao menos teoricamente - no ensino de língua portuguesa. Nesse livro, o autor identifica três concepções de linguagem subjacentes a todo o trabalho desenvolvido nas práticas de ensino: (1) linguagem como expressão do pensamento; (2) linguagem como instrumento de comunicação; (c) linguagem como forma de interação.

A cada concepção, o autor associa uma grande corrente dos estudos linguísticos: (1) a gramática tradicional; (2) o estruturalismo e o transformacionalismo; (3) a linguística da enunciação. A primeira concepção está ligada aos estudos tradicionais; a segunda, à teoria da comunicação; a terceira, aos estudos que situam a linguagem como "lugar de constituição de relaçóes sociais, onde os sujeitos se tornam sujeitos." (1984, p. 41).

Inserido nessa terceira corrente, Geraldi sugere que práticas de leitura, de produção de textos e de análise linguística se efetivem nas aulas de língua, de forma a corporificarem a concepção interacionista de linguagem na ação educativa. Duas questôes devem ser destacadas: a utilização da palavra "práticas" e das expressões "produção de textos" e "análise linguística". "Práticas são atividades voltadas para fins definidos individualmente ou coletivamente [...]" (GERALDI, 2010a, p. 79) e não são "transformáveis em mercadorias" (p. 79). Assim, sugerir atividades práticas como centro 
do fazer pedagógico significa não ter definição prévia do ponto de chegada, valorizar o processo mais do que o produto, considerar "as mil possibilidades de dizer" (p. 78).

Nessa perspectiva, Geraldi define as expressões "produção de textos" e "análise linguística", buscando afastar o ensino de língua portuguesa da "redação" e da supremacia do ensino de "gramática". Dessa forma, preconizando que o ponto de partida e de chegada do processo de aprendizagem devesse ser a produção de textos (GERALDI, 1984, 1997), o autor vê na análise linguística o instrumento para ensinar o aluno a melhor escrever e ler, porque não se limita à higienização do texto em seus aspectos gramaticais e ortográficos, mas trabalha "[...] com o aluno o seu texto para que atinja seus objetivos junto aos leitores a que se destina." (GERALDI, 1984, p. 74).

Suas ideias estão ancoradas em perspectiva bakhtiniana de linguagem, para quem a língua/linguagem nunca é abstrata, asséptica e neutra, porque produzida por sujeitos sócio-ideológicos em interação:

A verdadeira substância da língua não é constituída por um sistema abstrato de formas linguísticas nem pela enunciação monológica isolada, nem pelo ato psicofisiológico de sua produção, mas pelo fenômeno social da interação verbal, realizada através da enunciação ou das enunciações. (BAKHTIN, 1986, p. 123).

Estudar uma língua, então, significa inicialmente compreendê-la (a língua) como interação verbal, elegendo os textos/discursos produzidos em determinada esfera da comunicação sócio-ideológica (e que circulam no mundo) como objeto primordial de processo ensino-aprendizagem.

Em 1998, a publicação dos Parâmetros Curriculares Nacionais (PCN) desloca o foco das práticas linguageiras para os gêneros textuais. Sobre essa questão, Geraldi (2010a), uma voz dissonante entre os especialistas, ao analisar o trabalho que vem sendo desenvolvido na escola e a perspectiva que embasa os PCN, acaba por considerar esse novo objeto "mercadorias palatáveis ao sistema [...] definidos previamente, seriáveis, unificados e exigíveis em avaliações nacionais" (GERALDI, 2010a, p. 79). Esse é o motivo, segundo o autor, para a bem-sucedida caminhada realizada pelo ensino de gêneros na escola. Isto é, a perda de um "objeto de ensino", a partir da sugestão de práticas de leitura, escrita e análise linguística como alternativas para o ensino da gramática tradicional, movimento que se 
consolida nos anos 1980, tem seu retorno triunfal, a partir dos anos 2000, na definição de gêneros como centro do trabalho pedagógico.

Para o autor, então, o ensino de gêneros, ancorado em projetos neoliberais de sociedade e de educação, abandonou o conceito seminal de Bakhtin (2003):

[...] para que a mercadoria se tornasse palatável ao sistema, foi preciso esquecer a estabilidade relativa dos gêneros; o entrecruzamento genérico, a correlação genética com as atividades sociais e sua distinção entre gêneros primários e gêneros secundários deixa de ser processual para se tornar ontológica. Os gêneros passam a ser "entes" e não processos disponíveis para a atividade discursiva que se realiza no interior das esferas de atividades humanas. (GERALDI, 2010a, p. 79)

Para esse estudioso, imaginar que saber as características de um gênero habilita o estudante a produzir um discurso dentro deste gênero é uma crença inadequada, pois "[...] produzir um discurso (ou texto) exige muito mais do que conhecer as formas relativamente estáveis dos gêneros: há que se constituir como locutor, assumir o papel de sujeito discursivo, o que impóe necessariamente uma relação com a alteridade, com o outro." (GERALDI, 2010b, p. 81).

Paralelamente, o ensino de língua portuguesa no nosso país, ao longo desses últimos 40 anos, recebeu contribuiçôes importantes dos pesquisadores preocupados com os estudos de "letramento".

Esse conceito também adquire sentidos diversos e suas inúmeras (re) significações obrigam alguns teóricos a "rebatizarem" seus estudos, de forma a afastá-los do ideário de um modelo autônomo de letramento (STREET, 1995), caracterizado como uma aquisição individual pelo sujeito de um conjunto de habilidades de leitura e escrita, aprendido independentemente do contexto sociocultural. A perspectiva dos "novos estudos de letramento" origina-se, então, da necessidade de afastamento de trabalhos tradicionais e da necessidade de (re)compreensão da pedagogia crítica de Paulo Freire, compreendendo que a leitura e a escrita não podem ser abstraídas de suas práticas sócio-ideológicas. Logo, a aprendizagem de uma língua não pode ser reduzida ao domínio de um código, pois se encontra situada política e ideologicamente em um determinado contexto sócio-histórico (SOARES, 2005).

É nessa vertente de estudos que alguns autores definirão "letramento crítico" como a atitude de um professor que, comprometido com valores como justiça e luta contra as desigualdades sociais, aproveita as "brechas" 
de seu trabalho para analisar criticamente o caráter ideológico dos textos que circulam, visando ao desenvolvimento da consciência crítica. Duboc e Ferraz (2011, p. 22) afirmam que “[...] letramento crítico configura-se não como método preestabelecido, mas como postura diante de um texto com vistas à compreensão dos privilégios e apagamentos nas práticas sociais (cf. Comber, 2001)."

Torna-se fundamental registrar que, em relação ao ensino de língua portuguesa, o termo letramento, que começa a ser utilizado no Brasil nos anos 1970, já carrega toda a carga semântica de criticidade da expressão "letramento crítico", utilizado, este último, nos estudos de línguas adicionais (estrangeiras, até bem pouco tempo). O adjetivo "crítico", nessa área, reforça as diferenciaçôes que o distanciam de estudos tradicionais de letramento, marcando a opção por uma educação que leve a uma sociedade mais igualitária, através da conscientização de que toda leitura e escrita é situada, dependente das relações de poder que ali são constituídas. Como diz Mattos (2011, p. 69):

A dimensão crítica do letramento envolve o reconhecimento e a consciência de que "todas as práticas sociais e, portanto, todos os letramentos, são socialmente construídas e 'seletivas': elas incluem algumas representações e classificações - valores, objetivos, regras, padrões, perspectivas - e excluem outras." (LANKSHEAR; SNYDER, GREEN, 2000, p. 31).

Portanto, utilizar "letramento" em relação ao ensino de língua materna já pressupõe tratar-se de letramento crítico. Ao acrescentar "crítico" ao título desta seção, estamos apenas destacando a necessidade de a aula de língua portuguesa superar a "ingenuidade" na análise dos textos (do mundo, portanto), em direção à criticidade, ou, nas palavras de Freire (2011a), à curiosidade epistemológica:

Não há para mim, na diferença e na "distância" entre a ingenuidade e a criticidade, entre o saber de pura experiência feito e o que resulta dos procedimentos metodologicamente rigorosos, uma ruptura, mas uma superação. A superação e não a ruptura se dá na medida em que a curiosidade ingênua, sem deixar de ser curiosidade, pelo contrário, continuando a ser curiosidade, se criticiza. Ao criticizar-se, tornando-se então, permito-me repetir, curiosidade epistemológica, metodologicamente "rigorizando-se" na sua aproximação ao objeto, conota seus achados de maior exatidão. (p. 31-32, grifos do autor). 
Outro aspecto torna-se importante: se os estudos de letramento, em língua materna, surgem imbuídos de uma perspectiva de criticidade, a abordagem e a proposta do professor Geraldi não dispensam ou colocam em segundo plano essa mesma perspectiva. Basta resgatar ideias presentes nos trabalhos publicados por ele a partir de 1980: a ênfase ao caráter político das gramáticas, a denúncia de simulação de interlocução presente nas aulas de redação, a necessidade de os alunos tornarem-se sujeitos-autores de seus textos. A referência reiterada desse pesquisador aos trabalhos de Paulo Freire, um dos autores-base para os estudiosos de letramento crítico, de quem Geraldi se ocupa, inclusive, em obras específicas, a exemplo de "A linguagem em Paulo Freire" (2005), é mais uma prova da defesa da escola como instância também responsável pela leitura significativa da palavra e do mundo. Por isso, embora em correntes de pensamento diferentes, o redimensionamento do ensino de língua portuguesa - proposto por Geraldi ou pelos estudos de letramento - é explicitamente marcado pelo viés da necessidade de a escola ocupar-se de uma análise crítica dos textos produzidos e consumidos nas diferentes esferas de atividades humanas.

Esperamos, na seção 3, comprovar essa necessidade, a partir do relato de algumas situaçóes vividas pelo nosso grupo de trabalho no espaço da sala de aula de língua materna. Antes disso, vamos definir a linha metodológica da pesquisa.

\section{Perspectiva metodológica}

O Projeto de Extensão-Pesquisa-Ensino, no qual os dados deste trabalho foram gerados, insere-se nos princípios da pesquisa-ação, definidos por Thiollent (2007). Para esse autor,

[...] a pesquisa-ação é um tipo de pesquisa social com base empírica que é concebida e realizada em estreita associação como uma ação ou com a resolução de um problema coletivo e no qual os pesquisadores e os participantes representativos da situação ou do problema estão envolvidos de modo cooperativo ou participativo. (p. 16)

Trata-se de pesquisa com forte interação dos atores implicados em uma ação coletiva. Por isso, as informaçôes são interpretadas de forma participativa, colaborativa ou cooperativa.

Para distingui-la de outros tipos de pesquisa, o autor reafirma o fato de que há necessidade de "[...] ação por parte das pessoas ou grupos 
implicados no problema sob observação" (p. 17). Assevera que não pode ser uma ação trivial, ao contrário, precisa ser problemática, merecendo investigação para ser elaborada e conduzida. Nessa perspectiva, a pesquisa-ação não se torna sinônimo de ativismo, porque “[...] com ela é necessário produzir conhecimentos, adquirir experiência, contribuir para a discussão ou fazer avançar o debate acerca das questôes abordadas" (THIOLLENT, 2007, p. 24).

Além disso, nossa pesquisa embasa-se em pressupostos transdisciplinares da Linguística Aplicada. Isso significa dialogar diretamente com diferentes áreas de conhecimento para a compreensão dos fenômenos apresentados. Logo, ideias de Paulo Freire (2011a, 2011b), educador de reconhecido prestígio internacional, serão de enorme importância na análise de dados, além de contribuiçôes do cientista político Emir Sader (2008) e da professora de Retórica Carolyn Miller (2009), entre outros.

Nossa pesquisa sustenta-se, ainda, em orientação bakhtiniana (BAKHTIN, 1986, 2003, especialmente) do estudo da língua/linguagem, considerando que a interação verbal deva ser o objeto central de um trabalho didático-pedagógico atualizado e produtivo em sala de aula.

Os dados gerados na pesquisa e apresentados nesse trabalho sofrerão análise de cunho qualitativo, tida como mais adequada para a investigação dos fatos concernentes à relação sujeito-linguagem, buscando resguardar a coerência interna da investigação.

\section{Análise de alguns episódios de aulas de língua portuguesa}

Os extratos que vamos analisar ocorreram em 2013 e 2014, durante o desenvolvimento do Projeto de Extensão "Professor universitário e da educação básica, aluno de graduação e de escola: um encontro necessário". Essas cenas, recortes de aulas de língua portuguesa, ocorreram em três turmas distintas de escolas públicas, todas de primeiro ano de ensino médio. Como já dito, nos encontros entre professor universitário, docentes de língua portuguesa da escola básica e alunos de graduação, o fazer do dia a dia tornou-se foco de atenção, buscando construir alternativas para a sala de aula.

\section{Episódio 1:}

Os alunos foram desafiados a criar uma revista, desde a definição de uma temática, o público-alvo, a constituição interna, a capa, ou seja, idealizaram, planejaram e confeccionaram os exemplares, destinados à circulação escolar. Para a realização desse trabalho, foram organizados 
em grupos, e alguns textos foram estudados, sempre na perspectiva de seu funcionamento em determinada esfera discursiva/social.

Ao analisar anúncios publicitários, um fato chamou a atenção da professora da turma de primeiro ano de ensino médio. Todos os 37 alunos que dela participavam no ano de 2014 responderam afirmativamente à questão número 3 de um conjunto de perguntas sobre um anúncio publicitário de produto para lavar os cabelos. Tratava-se de texto retirado de revista de grande circulação nacional, no qual a atriz Grazi Massafera "anuncia" o shampoo Elsève, da indústria L'oréal. A questão 3 indagava: "Você acredita que a atriz utiliza o produto no dia a dia? Por quê?" Todos os discentes responderam afirmativamente à questão. As justificativas dadas pelos estudantes relacionavam-se à qualidade do shampoo ("é um bom produto", "deixa o cabelo lindo").

Costa (2009), em seu Dicionário de Gêneros, afirma o seguinte sobre "anúncio":

Como publicidade, trata-se de uma mensagem que procura transmitir ao público, por meio de recursos técnicos, multissemióticos e através dos veículos de comunicação, as qualidades e os eventuais benefícios de determinada marca, produto, serviço ou instituição. (p. 32).

A escolha da atriz que fará a campanha publicitária não é aleatória, como sabemos. Trata-se, como nos ensina Costa (2009), de estratégia para transmitir benefícios de determinada marca. Assim, um anúncio de shampoo exige um profissional bonito (nos padrões estabelecidos pela sociedade em determinado contexto histórico) e, obviamente, com um cabelo tratado, saudável e também bonito.

Recentemente, o site MSN publicou matéria intitulada " 6 casos de celebridades que não usam os produtos que vendem" ${ }^{2}$. Na reportagem estavam, entre outros, a apresentadora Angélica, anunciando produtos da Perdigão, sendo declaradamente vegetariana; Roberto Carlos, anunciando carne bovina para a Friboi, sendo, ele também, vegetariano; a cantora Sandy, propagandeando a cerveja Devassa, quando já havia declarado publicamente não tomar a bebida por achá-la amarga. Esses anúncios foram motivo de

\footnotetext{
${ }^{2} 6$ casos de celebridades que não usam os produtos que vendem. Disponível em: http://www. $\mathrm{msn} . \mathrm{com} / \mathrm{pt}$-br/dinheiro/economiaenegocios/6-casos-de-celebridades-que-n\%c3\%a3o-usamos-produtos-que-vendem/ss-AA8MptN?ocid=iehp\#image=1. Acesso em: 10 jan. 2015.
} 
polêmica entre o público-leitor. No caso do texto protagonizado por Roberto Carlos, foi rejeitado, por falta de legitimidade e credibilidade. Os produtos da Perdigão ficaram menos prejudicados pelo fato de a apresentadora Angélica figurar com a família, propiciando a interpretação de que o sacrifício - comer salsicha de cachorro quente sendo vegetariana - valeria a pena em favor do convívio com o marido e os filhos.

Assim, a credibilidade do produto anunciado passa pela escolha acertada dos elementos que constituirão o anúncio publicitário. Nesse sentido, os alunos, ao responderem afirmativamente à questão proposta, permitem que a meta da empresa anunciante seja alcançada, visto que enreda o interlocutor do texto em sentidos desejados por ela.

Concomitantemente, como estudantes do ensino médio, demonstram dificuldades para "des-velar" o jogo discursivo construído pelo gênero anúncio. Na visão de Sader (2008), trata-se do caso em que o estudante pode explicar o que lê, mas não entende o fenômeno. "Explicar é reproduzir o discurso midiático, entender é desalienar-se, é decifrar, antes de tudo, o mistério da mercadoria." (SADER, 2008, p. 18).

Vale o registro de que, nos encontros subsequentes a essa aula, o grupo de Extensão empenhou-se em organizar atividades de análise de variados anúncios, para auxiliar os discentes a construírem outras compreensões possíveis para a constituição e o funcionamento desse gênero discursivo, consequentemente, da esfera publicitária, seus outros textos constitutivos e sua influência no nosso meio social.

A lembrança das primeiras palavras de Bakhtin (2003), na clássica definição de gênero discursivo, é oportuna neste momento. Esse autor referiase aos diversos "campos da atividade humana" que "elaboram os seus tipos relativamente estáveis de enunciados” (p. 271), não o contrário. Os gêneros são determinados pelas especificidades de uma esfera de comunicação. Nesse sentido, a resposta dos alunos pode refletir o esquecimento sua "correlação genética" com as atividades sociais (GERALDI, 2010a, p. 79).

\section{Episódio 2:}

Ao trabalhar com o conteúdo "adjetivo", a professora apresentou aos alunos dois slides. No primeiro, uma pessoa estava sendo retratada do peito para cima, num fundo neutro. Tratava-se de um idoso, negro, sem dentes, barbudo e com o cabelo desalinhado. No segundo, duas pessoas vestidas 
de branco, sorridentes, abraçadas, retratadas de corpo inteiro. Ambas eram muito jovens, brancas; a moça, muito loura. A aula foi conduzida de forma a que os alunos descrevessem as imagens apresentadas. Na primeira, houve indução da professora para que os alunos chegassem ao adjetivo "feio", na segunda imagem, o adjetivo escolhido foi "bonitas". Na sequência da aula, a professora expôs o grau e o número dos adjetivos com exemplos de frases menos "marcados" ideologicamente.

É claro que podemos questionar a postura da professora e sua nãointenção em designar o negro pobre de "feio" e as pessoas brancas, louras de "bonitas", mas, como afirma Bakhtin (1986, p. 95):

$\mathrm{Na}$ realidade, não são palavras o que pronunciamos ou escutamos, mas verdades ou mentiras, coisas boas ou más, importantes ou triviais, agradáveis ou desagradáveis etc. A palavra está sempre carregada de um conteúdo ou de um sentido ideológico ou vivencial. É assim que compreendemos as palavras e somente reagimos àquelas que despertam em nós ressonâncias ideológicas ou concernentes à vida. (grifos do autor)

O Círculo de Bakhtin $(1986,2003)$ define a apropriação das vozes sociais como processo inerente à constituição de cada sujeito. Para o grupo, essas vozes carregam sempre um valor apreciativo constituído em determinado lugar sócio-histórico.

Um dos alunos de graduação participantes do encontro sugeriu que poderia haver preconceito nas palavras da professora, até porque, como diz Leite (2008, p. 21) "[...] o preconceito pode construir-se sobre o que nem foi pensado, mas apenas assimilado culturalmente ou plasmado em irracionalidade, emoções e sentimentos."

Isso significa que nem sempre temos consciência da repercussão das atitudes que tomamos diante de uma situação, porque nos apropriamos de palavras e ideias existentes em um determinado contexto, sem percebermos a amplitude que essas palavras e ideias podem tomar. Para alguns sujeitos do grupo de trabalho, a distinção entre feio e bonito revelou preconceito, para outros não. Essa diferença de avaliação precisou ser explicitada para que novas formas de pensar a questão fossem reveladas.

Ao diferenciar uma concepção 'bancária' de uma concepção humanista de educação, Freire (1997, p. 17) afirma que a concepção problematizadora (humanista), "[...] ao desafiar os educandos, através de situações existenciais concretas, dirige seu olhar para elas, com o que aquilo que antes não era percebido destacado passa a sê-lo." Exatamente isso foi o que ocorreu nesse 
encontro do grupo em que uma "simples" aula de "adjetivos", um termo metalinguístico, foi foco de análise.

\section{Episódio 3:}

Ao discutir com os alunos o tópico "gêneros escritos e gêneros orais", procurando desfazer a relação dicotômica estabelecida tradicionalmente entre essas duas modalidades e enfatizando as relações de dependência da fala e da escrita na constituição de vários textos, a professora perguntou aos estudantes se o Jornal Nacional, programa de Rede Globo, era oral ou escrito. Os discentes se dividiram na formulação de uma resposta; para alguns, oral, para outros, escrito.

Em outra aula, conforme o acordado no grupo de Extensão, a análise de uma cena de telenovela pareceu elucidativa o suficiente para auxiliar a maioria da turma a construir o conceito de "escrita oralizada". Um dos estudantes resolveu, na sequência, questionar relações entre oralidade e escrita em programas de entrevista e em programas de auditório. O debate que se seguiu foi bastante intenso.

"E o Big Brother Brasil?" (BBB), perguntou um dos integrantes da turma. A unanimidade se estabeleceu: "é oral, por se tratar de um programa ao vivo em que as pessoas conversam espontaneamente", diziam os alunos. Um discente de Graduação, participante do nosso Projeto e presente a essa aula, resolveu dizer que havia uma espécie de "roteiro" guiando as falas dos participantes do BBB. Seu comentário gerou uma enorme balbúrdia na sala, e o resultado foi a atribuição ao graduando, pelos discentes de ensino médio, da alcunha de "louco".

A discussão ocorrida na aula seguinte, quando o referido aluno de Graduação apresentou uma revista em que havia uma reportagem intitulada "Realidade roteirizada" ${ }^{3}$, que discorria sobre o BBB, contribuiu para que posições fossem repensadas, embora o convencimento de todos em relação a também haver um roteiro escrito no referido programa televisivo não tenha sido atingido. Ademais, questôes "complementares" foram agregadas à central: "o público decide ou não as eliminaçôes?"; "quem paga um programa de televisão"; "há lei que regulamenta o que pode aparecer na tela ou não"?

${ }^{3}$ MORISAWA, Mariane. Realidade roteirizada. Lingua Portuguesa, São Paulo, ano 7, n. 76, p. 20-15, fev. 2012. 
O envolvimento dos estudantes nos fez investir em pesquisas conjuntas, a fim de dar resposta às questões formuladas. Partindo da concepção de Freire de que os programas escolares preconcebidos precisam ser substituídos por "[...] situaçõoes existenciais capazes de, desafiando os grupos, levá-los, pelo debate das mesmas, a posições mais críticas” (FREIRE, 1963, p. 11), consideramos que práticas efetivas de leitura foram necessárias, para que as perguntas tivessem uma possibilidade de resposta.

Não podemos atribuir valor menor para a questão da "compreensão" de programas televisivos em sala de aula. Conhecemos o poder deste veículo de comunicação na nossa sociedade, não só pela sua inserção nos lares brasileiros - de acordo com o senso do IBGE (2010), em mais de 96\% dos lares há TV em cores, mas apenas em 31,5\% dos domicílios há acesso à internet - mas também pela função adquirida pela televisão de formadora de opinião, ou, como asseveram Tosta e Melo (2006), uma das grandes "educadoras" da atualidade.

Nesse sentido, não basta analisar as entrelinhas de uma cena da "ingênua" novelinha das $18 \mathrm{~h}$ com nossos alunos - trabalho incontestavelmente necessário - é fundamental, além disso, analisar a grade televisiva, o motivo de sucesso de alguns programas, as propagandas veiculadas em cada horário, entre outros aspectos. Trata-se de analisar o modus operandi do nosso tempo/ espaço, marcado pelo enfraquecimento da fronteira entre o público e o privado, pelo voyerismo, pela autoexposição e pela arte do self(MILLER, 2009), buscando justificativas para o que se vê (ou não) na telinha.

\section{Considerações finais}

A célebre frase "Ninguém educa ninguém, ninguém educa a si mesmo, os homens se educam entre si, mediatizados pelo mundo" (FREIRE, 2011 b, p. 95) torna-se relevante no contexto deste trabalho, ao considerar que o encontro de pessoas com crenças e saberes diferenciados (professor universitário e da educação básica, alunos de escola e de Graduação) desencadeou o processo reflexivo que se estabeleceu nas salas de aula, propiciando, acreditamos, a superação, não a ruptura, de uma curiosidade ingênua para uma curiosidade epistemológica, embora esse processo não possa receber mensuração. Ensinar língua portuguesa exige clareza de que "a promoção da ingenuidade para a criticidade não se dá automaticamente", constituindo-se tarefa educativa precípua para "o desenvolvimento da curiosidade crítica, insatisfeita, indócil” (FREIRE, 2011a, p. 33). 
Os conteúdos das aulas não são "neutros" ou puramente metalinguísticos. Nesse sentido, uma aula de adjetivos nunca é apenas uma aula de adjetivos. Também não podem ser considerados espaços para discussão apenas aqueles em que propositadamente elegemos temas polêmicos para participarem das nossas aulas, a exemplo de aborto, maioridade penal, pena de morte... Como diz Freire (2011b, p. 97-98): “[...] a educação problematizadora, de caráter autenticamente reflexivo, implica um constante ato de desvelamento da realidade; [...] busca a emersão das consciências, de que resulte sua inserção crítica na realidade." (grifos do autor).

Problematizar situações, desnaturalizá-las é objetivo de um trabalho que privilegie a reflexão dos textos/discursos que materializam gêneros discursivos, compreendidos na sua relação com (e dependência das) atividades humanas, nunca como "entes", conforme crítica de Geraldi (2010a).

Uma prática de ensino de leitura, portanto, exige colocar os textos que oferecemos aos nossos alunos (sejam orais ou escritos) em confronto - por isso uma concepção problematizadora de educação, em termos freireanos para que as mentiras e verdades, coisas boas e más, importantes ou triviais (palavras de Bakhtin) que apresentamos, sejam alvo de análise, visando refletir sobre o dito e o não-dito do texto formulado. Também para os estudiosos da corrente do letramento crítico, "[...] a reflexão e a metaconversa fomentadas precisam ir muito além do linguístico para serem capazes de localizar o aluno com relação ao não-dito - não ao implícito, mas ao silenciado: o público ao qual o texto serve e a ideologia que ele dissemina." (MATTOS e VALÉRIO, 2010, p. 148). Essa é uma tarefa indispensável, quando se opta por contribuir para a formação de sujeitos críticos.

\section{Referências}

BAKHTIN, Michail (Volochinov). Marxismo e filosofia da linguagem. $3^{\mathrm{a}}$ ed. Tradução de Michel Lahud e Yara Frateschi Vieira. São Paulo: Hucitec, 1986.

BAKHTIN, Michail. Estética da criação verbal. Tradução de Paulo Bezerra. São Paulo: Martins Fontes, 2003.

CERTEAU, Michel de. A invenção do cotidiano. $5^{\mathrm{a}}$ ed. Tradução de Ephraim Ferreira Alves. Petrópolis, RJ: Vozes, 2000.

COSTA, Sérgio Roberto. Dicionário de gêneros textuais. 2[ ed. rev. e ampl. Belo Horizonte: Autêntica, 2009. 
DUBOC, Ana Paula; FERRAZ, Daniel Mello. Letramentos críticos e formação de professores de inglês: currículos e perspectivas em expansão. Revista $X$, v. 1, p. 19-32, 2011.

FREIRE, Paulo. Conscientização e alfabetização: uma nova visão do processo, 1963. Disponível em: http://acervo.paulofreire.org/xmlui/search?fq=location.coll\%3A6. Acesso em: abr. 2013.

FREIRE, Paulo. Papel da educação na humanização, 1997. Disponível em: http:// acervo.paulofreire.org/xmlui/search?fq=location.coll\%3A6. Acesso em: abr. 2013. FREIRE, Paulo. Pedagogia da autonomia: saberes necessários à prática educativa. $2^{\mathrm{a}}$ imp. 43a ed. Rio de Janeiro: Paz e Terra, 2011a.

FREIRE, Paulo. Pedagogia do oprimido. $50^{\mathrm{a}}$ ed. rev. e atual. Rio de Janeiro: Paz e Terra, 2011b.

GERALDI, João Wanderley. O texto na sala de aula. Paraná: Assoeste, 1984. GERALDI, João Wanderley. Portos de Passagem. $4^{\mathrm{a}}$ ed. São Paulo: Martins Fontes, 1997.

GERALDI, João Wanderley. A linguagem em Paulo Freire. Educação, Sociedade \& Culturas, n. 23, p. 7-20, 2005.

GERALDI, João Wanderley. Deslocamentos no ensino: de objetos a práticas, de práticas a objetos. In: GERALDI, João Wanderley. A aula como acontecimento. São Carlos: Pedro \& João Editores, p. 71-80., 2010a.

GERALDI, João Wanderley. Texto e discurso. In: GERALDI, João Wanderley. Ancoragens: estudos bakhtinianos. São Carlos: Pedro \& João Editores, p. 75-82.,2010b. INSTITUTO BRASILEIRO DE GEOGRAFIA E ESTATÍSTICA (IBGE). Sintese de Indicadores Sociais: uma análise das condições de vida da população brasileira. Brasília, DF, 2010. (Estudos \& Pesquisas: informação demográfica e socioeconômica 27). Disponível em: http://www.ibge.gov.br/home/estatistica/ populacao/condicaodevida/indicadoresminimos/sinteseindicsociais 2010/ SIS_2010.pdf. Acesso em: 23 jan. 2015.

LEITE, Marli Quadros. Preconceito e intolerância na linguagem. São Paulo: Contexto, 2008.

MATTOS, Andréa Machado de Almeida; VALÉRIO, Kátia Modesto. Letramento crítico e ensino comunicativo: lacunas e interseçōes. Revista Brasileira de Linguística Aplicada, Belo Horizonte, v. 10, n. 1, p. 135-158, 2010.

MATTOS, Andréa Machado de Almeida. O ensino de inglês como língua estrangeira na escola pública: novos letramentos, globalização e cidadania. 2011. 262 f. Tese (Doutorado em Estudos Linguísticos e Literários em Inglês do Departamento de Línguas Modernas) - Faculdade de Filosofia, Letras e Ciências Humanas da Universidade de São Paulo, São Paulo, 2011. 
MILLER, Carolyn R; SHEPHERD, Dawn. Blogar como ação social: uma análise do gênero weblog. In: MILLER, Carolyn R. Estudos sobre gênero textual, agência e tecnologia. Tradução de Judith Hoffnagel. Recife: Editora Universitária da UFPE, p. 61-92, 2009.

SARTORI, A. T. A universidade na escola: formação profissional através de práticas de letramento crítico. In: V Taller Internacional de Formación Universitaria de profesionales de Ia Educación, 2014, Havana, Cuba. Memorias - Universidade 2014 - 9 Congreso Internacional de Educación Superior, 2014. CD-ROM.

SADER, Emir. Prefácio. In: MÉSZÁROS, István. A educação para além do capital. Tradução de Isa Tavares. 2a ed. São Paulo, Boitempo, 2008. (Mundo do trabalho). SOARES, Magda. Alfabetização e letramento têm o mesmo significado? Revista Pátio, ano IX, n. 34, p. 50-52, maio/jul. 2005.

STREET, Brian. Social literacies: critical approaches to literacy in development, ethnography and education. London and New York: Longman, 1995.

THIOLLENT, Michel. Metodologia da pesquisa-ação. 15a ed. São Paulo: Cortez, 2007. (Coleção Temas Básicos de Pesquisa-Ação).

TOSTA, Sandra; MELO, José Marques. Midia e educação. Belo Horizonte: Autêntica Editora, 2006. (Temas Educação).

Data de submissão: 15/03/2015. Data de aprovação: 19/05/2015. 